391 By the Numbers: The Inaugural 2018 TLC at APSA Survey Results

3962019 Annual Meeting Information

397 Meet the 2019-20 APSA Minority Fellows
401 Rules, Polarization, and the Future of the Senate 404 What Role Do Interest Groups Play in House Committees?

410 Members of the Month

411 International

\title{
By the Numbers: The Inaugural 2018 TLC at APSA Survey Results
}

\section{Renée Van Vechten, Co-chair, TLC at APSA Planning Committee \\ Alison Rios Millett McCartney, Co-chair, TLC at APSA Planning Committee}

\section{INTRODUCTION}

In the last edition of $P S$, we briefly reviewed the inaugural "Teaching and Learning Conference at APSA" (TLC at APSA), a day-long event that took place on Saturday, September 1, 2018 during the APSA annual meeting. By increasing professional development opportunities and widening access to high-quality pedagogical resources, the conference-within-a-conference met one of APSA's core objectives: to promote quality teaching and education about politics and government. As we discuss in this report, results from surveys administered during the event suggest both that this conference and the stand-alone TLC provide complementary venues for promoting political science education across the discipline.

To recap, the Saturday event began with a breakfast and keynote speech on creating inclusive, more civil campuses by Dr. Nancy Thomas, Director of the Institute for Democracy and Higher Education at the Jonathan Tisch College of Civic Life at Tufts University. Participants then could attend one of five interactive workshops, followed by a networking lunch sponsored by CQ Press. After lunch, attendees chose among four teaching cafés, followed by traditional panels organized into three tracks: Civic Engagement; Simulations and Games; and Technology and Innovative Pedagogy. The closing reception provided a comfortable setting for further networking and socialization, and was cosponsored by the Political Science Education section and the APSA Committee on the Status of Community Colleges in the Profession. Participants were free to come and go between TLC at APSA and the annual conference proceedings, although we encouraged attendees to stay for the entire day. This structure incorporated key elements of the standalone TLC (mini tracks and workshops) and introduced new ones (teaching cafés and less emphasis on tracks). An overview of the conference events can be found in the January 2019 edition of PS (McCartney and Van Vechten, 2019). As promised at the conclusion of that article, here we review participation and assess attendees' experiences. Based on this data we also develop recommendations for future APSA-sponsored teaching and learning conferences.

\section{METHODOLOGY}

To capture the responses of those who might have attended only parts of the conference, two separate paper questionnaires were administered to participants at two different times. An estimated 227 persons attended the event, and the first version was collected from 133 individuals, whereas the second drew responses from 85 persons at the closing event ( 218 total; double responses were possible). APSA staff compiled the data and produced a summary of results (authored by Megan Davis), which forms the basis for this report. We also reviewed raw qualitative responses to open-ended questions.

Table 1 reveals few demographic differences between participants of the TLC at APSA and the annual meeting, although higher percentages of females attended all events (no tests for statistical significance were supplied), and both venues were dominated by non-Hispanic white participants, who attended the TLC at APSA at even higher rates than the annual conference (an average of $74.6 \%$ compared to $64.3 \%$ at the annual meeting). Furthermore, the groups differed slightly in their mix of institutional types and ranks. TLC at APSA survey respondents were more likely to be faculty from BA-granting (over $7 \%$ higher) and two-year institutions (over $4 \%$ higher) rather than from $\mathrm{PhD}$-granting institutions (almost 10\% fewer than annual meeting respondents). Regarding faculty rank, assistant professors were less likely to attend the day-long conference (17.1\% TLC participants versus $31.8 \%$ annual meeting participants), but associate professors attended at higher rates $(26.4 \%$ TLC and $19.3 \%$ annual meeting). While their participation numbers were relatively low, adjuncts and lecturers attended at nearly twice the rates of the annual meeting (over $4 \%$ as opposed to only $2.3 \%$ at the annual meeting). Overall, it appears that those who have the security of tenure as well as those who occupy teaching-oriented positions were represented at higher rates at the TLC at APSA than at the regular annual conference.

\section{Participants' Views about Programming}

We posed several Likert scale questions in both surveys to capture participants' views of the TLC at APSA experience (see figure 1).

Overall, respondents strongly agreed or agreed that TLC at APSA was a wellorganized and structured experience (92.9\%), which met or exceeded their expectations (84.7\%) and provided useful programming and content (88.2\%). Responding to a similar question posed in the annual meeting survey, $83.7 \%$ of those who participated in TLC at APSA strongly agreed or agreed that the conference-within-a-conference met or exceeded their expectations. No "strongly disagree" responses were recorded on any survey. Based on these simple metrics, we might conclude that the first iteration of TLC at APSA was a success.

To widen our definition of success, however, we are compelled to consider a wider range of measures and to account for 
News

Table 1

Demographic Data from Participant Questionnaires

CHARACTERISTICS

QUESTIONNAIRE 1 QUESTIONNAIRE 2

2018 AM EVALUATION

Gender

\begin{tabular}{|c|c|c|c|}
\hline Female & $56.0 \%$ & $55.6 \%$ & $58.4 \%$ \\
\hline Male & $44.0 \%$ & $44.4 \%$ & $41.6 \%$ \\
\hline \multicolumn{4}{|l|}{ Race/Ethnicity } \\
\hline Black, Afro-Caribbean, or African American & $4.1 \%$ & $3.8 \%$ & $3.2 \%$ \\
\hline East Asian or Asian American & $5.0 \%$ & $5.0 \%$ & $8.7 \%$ \\
\hline Latino or Hispanic American & $4.1 \%$ & $5.0 \%$ & $4.8 \%$ \\
\hline Middle Eastern or Arab American & $4.1 \%$ & $2.5 \%$ & $3.2 \%$ \\
\hline Native American or Alaskan Native & $0.0 \%$ & $0.0 \%$ & $0.0 \%$ \\
\hline Native Hawaiian or Other Pacific Islander & $0.0 \%$ & $0.0 \%$ & $0.0 \%$ \\
\hline Non-Hispanic White or Euro-American & $70.3 \%$ & $78.8 \%$ & $64.3 \%$ \\
\hline South Asian or Indian American & $0.8 \%$ & $1.9 \%$ & $0.0 \%$ \\
\hline Other & $8.3 \%$ & $3.8 \%$ & $7.1 \%$ \\
\hline Prefer not to answer & $3.3 \%$ & $1.3 \%$ & $8.7 \%$ \\
\hline \multicolumn{4}{|l|}{ Position } \\
\hline Faculty in a PhD-Granting Program & $18.5 \%$ & $17.1 \%$ & $27.6 \%$ \\
\hline Faculty in a MA-Granting Program & $14.3 \%$ & $13.4 \%$ & $11.2 \%$ \\
\hline Faculty in a BA- Granting Program & $24.4 \%$ & $23.2 \%$ & $16.4 \%$ \\
\hline Faculty in a 2-Year College & $14.3 \%$ & $12.2 \%$ & $9.0 \%$ \\
\hline Adjunct Professor & $5.0 \%$ & $2.4 \%$ & $1.5 \%$ \\
\hline Post-Doctoral Fellow & $0.8 \%$ & $1.2 \%$ & $1.5 \%$ \\
\hline Academic Administration & $0.8 \%$ & $4.9 \%$ & $3.7 \%$ \\
\hline Graduate Student & $13.5 \%$ & $12.2 \%$ & $18.7 \%$ \\
\hline K-12 Teachers & $0.8 \%$ & $0.0 \%$ & $0.0 \%$ \\
\hline Employed Outside Academe & $4.2 \%$ & $8.5 \%$ & $3.0 \%$ \\
\hline Other & $3.4 \%$ & $4.9 \%$ & $7.5 \%$ \\
\hline \multicolumn{4}{|l|}{ Rank } \\
\hline Full Professor & $29.2 \%$ & $24.6 \%$ & $29.6 \%$ \\
\hline Associate Professor & $25.0 \%$ & $27.7 \%$ & $19.3 \%$ \\
\hline Assistant Professor & $15.6 \%$ & $18.5 \%$ & $31.8 \%$ \\
\hline Visiting Professor & $4.2 \%$ & $4.6 \%$ & $4.6 \%$ \\
\hline Lecturer & $8.3 \%$ & $6.2 \%$ & $10.2 \%$ \\
\hline Instructor & $4.2 \%$ & $4.6 \%$ & $2.3 \%$ \\
\hline Adjunct Professor & $5.2 \%$ & $3.1 \%$ & $2.3 \%$ \\
\hline Emeritus* & $1.0 \%$ & $1.5 \%$ & $0.0 \% *$ \\
\hline Other* & $7.3 \%$ & $9.2 \%$ & $0.0 \% *$ \\
\hline
\end{tabular}

*'Emeritus' and 'Other' were not options for rank in the 2018 Annual Meeting Evaluation

Note: The data presented here are from the 2018 TLC at APSA Paper Surveys. Two paper questionnaires were administered to TLC at APSA participants during the conference held on September 1, 2018. The first questionnaire was distributed to and collected from 133 participants during the luncheon. The second questionnaire was distributed to and collected from 85 participants at the end of the conference. 
shortcomings. As reported by the first wave of respondents during lunch, the most valuable components of TLC at APSA (to that point) had been the workshops that enabled them to add new lessons, ideas, and games/ simulations to their pedagogical toolkit (56.9\%). Respondents at the close of the conference also valued workshops (29.5\%), but prioritized panels that featured a deeper dive into the scholarship of teaching and learning (46.2\%). See figures 2 and 3 .
The second questionnaire contained an open-ended item asking respondents to provide additional suggestions, thoughts, and comments about TLC at APSA (see figure 4).

A plurality of comments offered suggestions for additional programming (such as themes for panels, subjects for workshops, and so forth), and over $12 \%$ gave unsolicited positive feedback that took the form of representative comments such as, "Overall, very useful for my teaching," and

\section{Figure 1}

\section{TLC at APSA Evaluation}

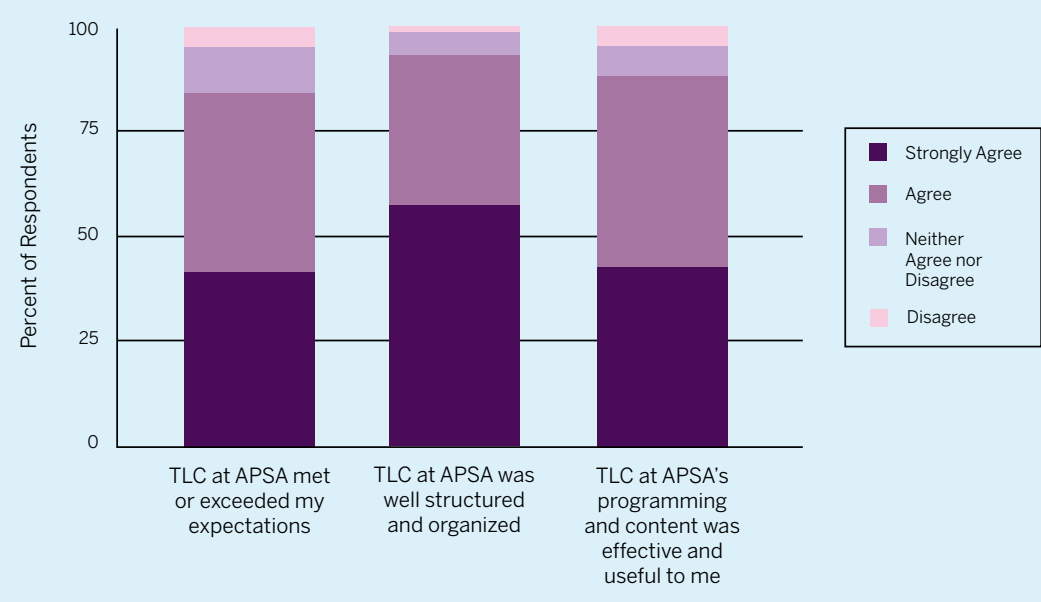

Figure 2

Questionnaire 1: Most Valuable Portions of TLC at APSA

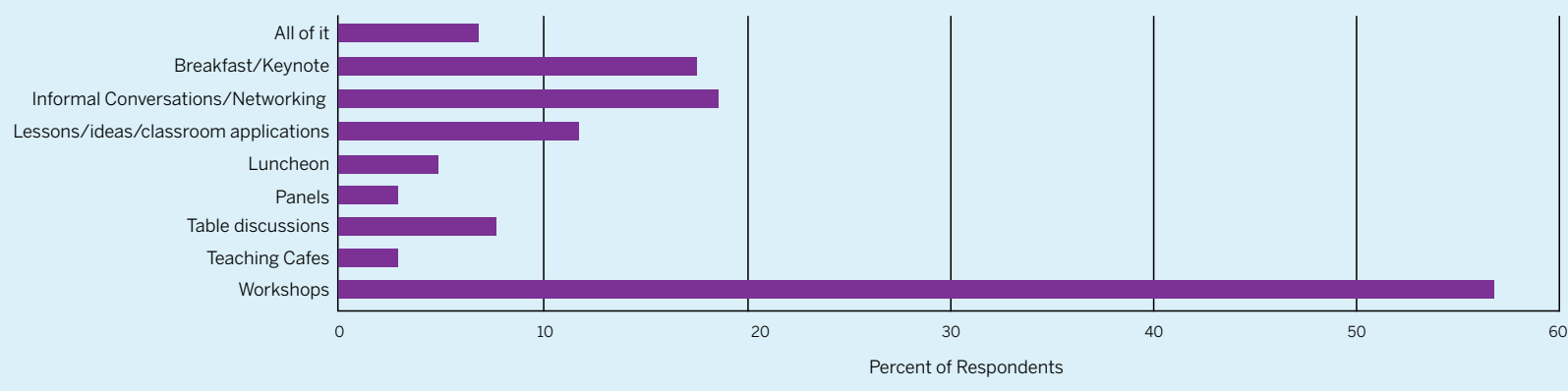

Figure 3

Questionnaire 2: Most Valuable Portions of TLC at APSA

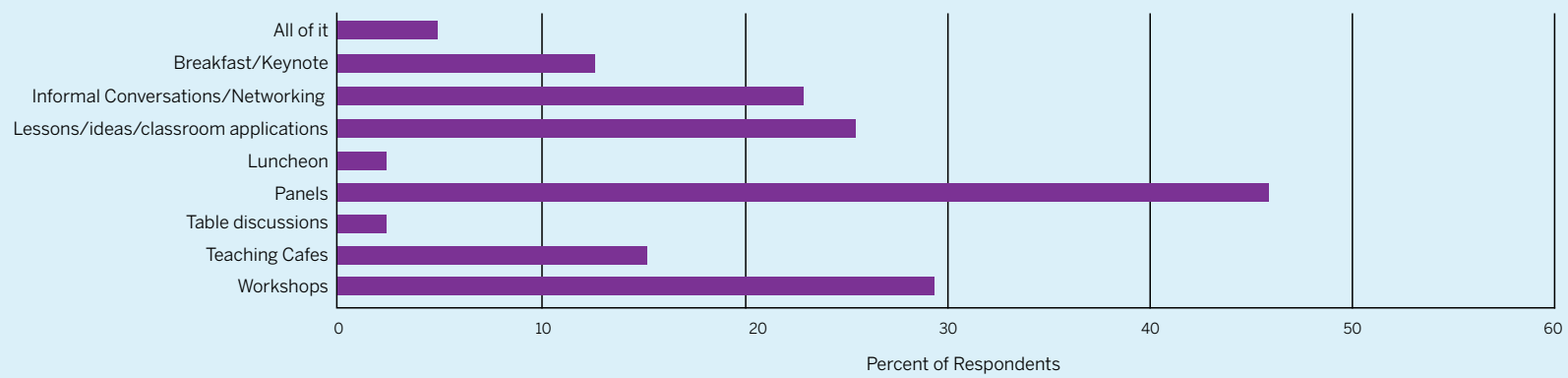

"Definitely will take everything from these courses back with me." Many participants appreciated the opportunities to network and converse with others about similar issues: "[At] Luncheon - I got to sit \& meet people in the field who are concerned with the same issues."

On the downside, nearly $19 \%$ gave feedback about the scheduling, which centered mostly on unavoidable conflicts with regular annual meeting events and how the TLC at APSA could be more conveniently timed. Said one, "I had to miss a lot of the miniconference because of APSA obligations," and another: "I had to choose between headline' panels in my subfield and TLC content, [and I] would like to be able to do both." This category of comments conveyed a hope that solutions to these dilemmas could be found, but as we discuss next, some inevitable conflicts in scheduling will persist.

\section{Conference-within-a-Conference vs. Standalone Conference}

The TLC at APSA was conceived of as an alternative to (but not a replacement for) a regular, standalone conference that has been offered annually for 14 years. Were different APSA constituents attracted to this conference? The survey showed that a majority of respondents had never 
attended a TLC prior to the 2018 TLC at APSA (56.3\%). Among the remaining 44\% who had attended at least one regular TLC, $14.4 \%$ had attended only one; $16.7 \%$ had attended between two and four; and $13.6 \%$ had attended five or more. In other words, the annual conference was successful in attracting a new group of attendees, many of whom verbally communicated their excitement at "finally" being able to attend a TLC due to given travel budgets that normally limit them to one conference annually, or to a conference located nearby (geographically).

Indeed, about a third of respondents (32.8\% in the first survey and $26.8 \%$ in the second) said they were likely to only attend a future TLC at APSA, but about half of all first-timers ( $48.4 \%$, not in figure 5 ) reported that they would attend a TLC at APSA in the future. Figure 5 captures participants' intentions to attend future Teaching and Learning Conferences.

Among all respondents, convenience (34.7\%), the professional importance of the TLC (31.6\%), and cost (29.5\%) were cited as the most common reasons they would attend future Teaching and Learning Conferences. As figure 6 shows, a clear benefit of attending the TLC at APSA was that there was no additional cost to attend, as the conference was included in the annual meeting fee.

Support for a regular, standalone TLC remains strong. Over half of respondents to both questionnaires stated that they are likely to attend both a TLC at APSA and a standalone TLC in the future $(53 \%$ and $56.3 \%$, respectively). Open-ended comments contained a subset of statements such as, "Bring back the yearly standalone conference! And keep TLC at APSA!” Very few reported that they were unlikely to attend a future TLC at APSA or standalone TLC (5.9\% in the first survey and $7.3 \%$ in the second). When respondents considered the professional importance of the Teaching and Learning Conferences, issues of cost and convenience were less crucial. Of those who said that the conference is professionally important, the vast majority responded that they are likely to attend both a future TLC at APSA and a standalone TLC (93.3\%). Responses indicated that attending the conference in any form is valuable.

\section{DISCUSSION AND}

\section{RECOMMENDATIONS}

The patterns discerned among closed- and open-ended responses and in feedback gleaned from conference-goers was that TLC at APSA is an innovation worth keeping

\section{Figure 4}

\section{TLC at APSA Suggestions/Comments}

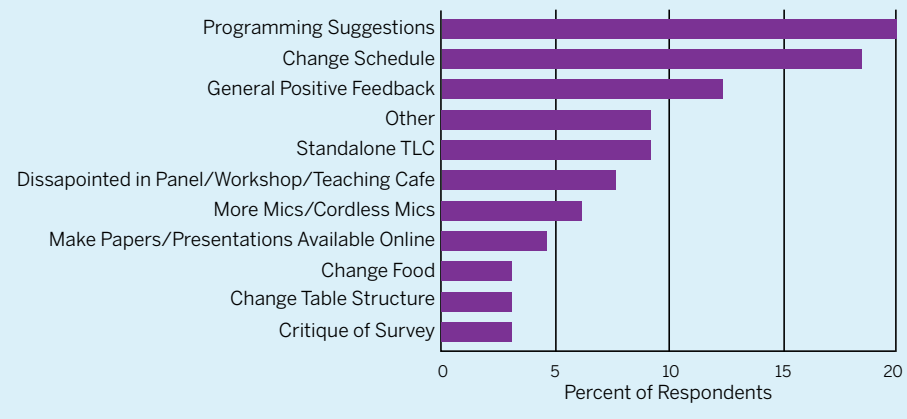

Figure 5

Future TLC Attendance
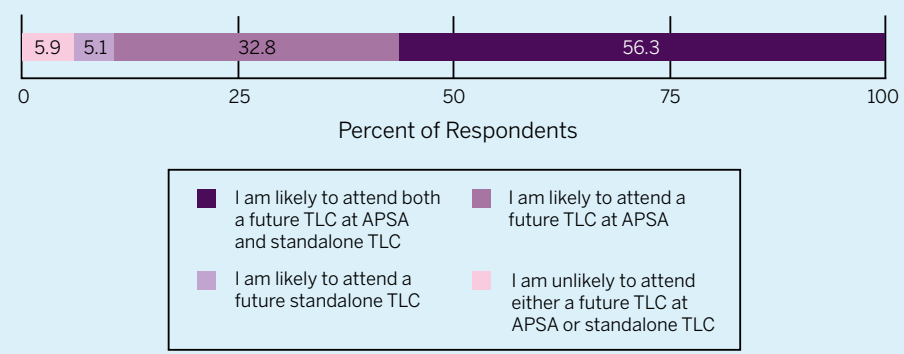

Figure 6

Future TLC Attendance Considerations

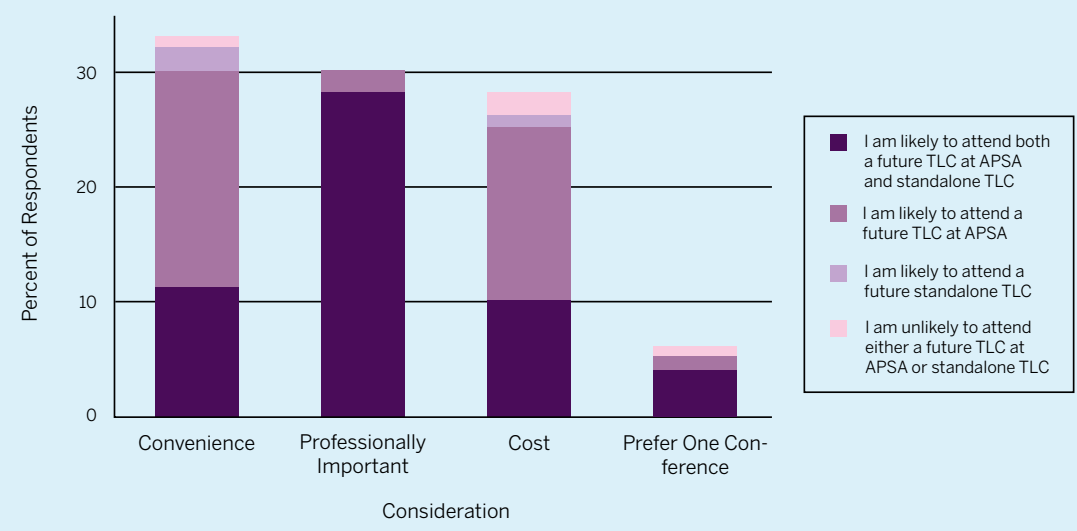

and that it complements-but should not replace-the regular, standalone Teaching and Learning Conference. This new format clearly serves political scientists who would not otherwise be able to attend a regular TLC; many first-timers were enthusiastic about the opportunity to connect with others about pedagogy, as they had been unable to find sufficient funding to attend a separate conference.

On the one hand, the inaugural event demonstrates that the two conferences differ in significant ways. The shorter timeframe of TLC at APSA lends itself more easily to hands-on experiences and research panels that can be sampled throughout the day by many attendees on a drop-in basis. On the other hand, the regular, standalone TLC is organized by themed tracks that convene repeatedly. During two-and-ahalf days, TLC conference-goers have the opportunity to evaluate a concentrated set of research papers collaboratively, attend various workshops, discuss research at length in both formal and informal settings, and create professional relationships that 
are primed through online interaction prior to the conference, strengthened through iterative discussions, and form the basis for meaningful collaborative work after the conference. As one (representative) respondent put it: "Please keep the standalone TLC-this was great but it didn't have the power of that event."

The issue of "event power" is reflected in several comments which highlighted three issues, only part of which can be addressed proactively, as these issues arise from the contrasting nature of the two conference formats. First is the desire among many participants (presumably those who have attended TLC standalone conferences) for more intensive focus on developing the scholarship of teaching and learning, which is more difficult to conjure during a single fast-paced annual conference day where many individuals are cycling in and out. In contrast, the standalone conference devotes "breathing room" to examine pedagogical research, provides a wider variety of targeted panels, and enables deeper discussion that helps participants refine their research and pedagogical approaches. This process leads to more opportunities for more scholars to disseminate high-quality research.

The second and third issues are intertwined: space and size. Spatially, during the annual meeting conference the venue options and room configurations were limited (although APSA staff worked hard to situate all program events in contiguous rooms). Some respondents noted that room layouts were not conducive to sustained discussion and collaboration, hallmark features of the standalone conference.

Relatedly, attendees could choose which events to attend and circulate among them without penalty, but this led to some audience maldistribution at workshops and panels. For example, the highly popular workshop focusing on classroom-based political discussion in the Trump era attracted the largest audience $(n=75)$, but a competing workshop attracted fewer than 10 persons. About $40 \%$ of respondents (40.0\% in survey one and $42.4 \%$ in survey two) attended the civic engagement panels, meaning that there were insufficient accommodations and too many participants to capture the interactive workshop dynamic of the standalone TLC tracks.

This points to a secondary issue: not only was panel time tightly compressed compared to the standalone conference, but it was also impossible to obtain the same level of investment from participants-qualities attached to the concentrated nature of the standalone TLC, a feature that elevates the development of teaching methods through careful methodology and the dissemination of research, both of which lie at the core of quality political science education. Preregistration for individual workshops could help mitigate this problem by providing early indicators of their popularity, but such a constraint could also change the "open and welcome to all" orientation of the daylong conference.

Some of these problems can be better addressed in future iterations but will likely take several attempts to resolve. Future organizers could explore expanding the number of workshops and panels to better accommodate the numbers of attendees, or could deliberately redistribute attendance among events, but this would require more advanced planning within the APSA annual conference structure and might sacrifice attendees' sense of freedom. While the number of attendees at any given event can be hard to predict, some changes at the pre-registration stage and planning could address these concerns and increase the impact of TLC at APSA.

In terms of other logistical issues, future organizers of TLC at APSA will be faced with scheduling issues that will not be easily resolved. The timetable for a daylong event must be coordinated with the APSA annual meeting schedule to minimize interruptions, which can create odd gaps (as we found with a break between short teaching cafés and lunch). We do not recommend moving the event to Wednesday, as suggested by only a few respondents, because this tends to increase costs for participants by lengthening their stay and interfering with teaching schedules, considerations that are particularly important for those at teaching-intensive institutions. In short, conflicts with regularly scheduled events are inevitable, and frequent circulation among attendees should be expected.

Concerns over the financial costs and locations of both conferences were also raised. Higher education institutional budgets run on an academic calendar; thus, so do most attendees' budgets. Meanwhile, funding is shrinking for many, not growing. In addition, for many, proximity drives the decision to attend. To minimize the effects of "drawing from the same pool" of potential attendees, we recommend that the two conferences be located in different regions in any given academic year. In short, an optimal outcome would be that everyone could afford to attend at least one of these conferences per year.

Conference "reach" and who attends should continue to drive planning decisions. Preliminary results suggest this new annual meeting venue attracts attendees who have the time, job security, limited travel budgets, and/or institutional focus that makes attending TLC at APSA professionally appealing and useful. This parting comment was echoed by several other respondents and encapsulates a major takeaway: "I have found each session [...] necessary and enriching and I'm excited to bring all I've learned to my teaching in 2018-2019; TLC + TLC at APSA are necessary and need to be promoted."

\section{FINAL COMMENTS}

Overall, we conclude that the first iteration of APSA at TLC was a success and should be continued. Importantly, the day-long conference attracted a group of previously underserved constituents-newcomers who have never been able to attend a standalone TLC-as well as APSA members who have benefited from previous TLCs. It's clear that the two different conference formats serve related (not identical) goals and needs of various APSA members. Distinct institutional contexts and environments are conducive to different types of programming, and the expectations, goals, dynamics, and outcomes associated with each event also vary. More data is needed to discern how these two conference options may complement each other in terms of content and participation, with special attention paid to the effects of not holding a TLC in 2019. By building on lessons learned from the inaugural conferencewithin-a-conference, APSA has the tools to institutionalize both TLC conferences and to make them more accessible and fruitful for the wide variety of participants who engage in them.

\section{A C K N O W L E D G M E N T S}

We would like to thank Tanya Schwarz and Megan Davis at APSA for their help in compiling the data and preparing an internal APSA document used for this report, and Steven Smith, APSA Director, for leading the initiative to bring TLC to the annual conference.

\section{R E F E R E N C E S}

McCartney, Alison Rios Millett and Renée Van Vechten. 2019. "Teaching and Learning Conference-within-A-Conference Launched at APSA Annual Meeting in Boston." PS: Political Science \& Politics 52 (1): 157-58. 